\title{
The effect of quenching parameters on the structure and properties of radiation-resistant austenitic steel for the VVER core baffle
}

\author{
I. V. Teplukhina ${ }^{1}$, A.S. Tsvetkov ${ }^{\dagger, 1,2}$, A. V. Kosulnikova ${ }^{1}$ \\ †a.s.tsvetkow@gmail.com \\ ${ }^{1}$ NRC "Kurchatov institute” — CRISM “Prometey”, 49 Shpalernaya St., St. Petersburg, 191015, Russia \\ ${ }^{2}$ Peter the Great Saint Petersburg Polytechnic University, 29 Polytechnicheskaya St., St. Petersburg, 195251, Russia
}

\begin{abstract}
The VVER core baffle is one of the main elements of the reactor internals and serves to protect the reactor vessel from neutron irradiation. The material of the VVER core baffle experiences the greatest radiation loads and has the maximum temperature due to $\gamma$-heating as a result of irradiation. Neutron irradiation leads to radiation swelling, reduction of plasticity and crack resistance of the material. Steel grade $08 \mathrm{H} 18 \mathrm{~N} 10 \mathrm{~T}$ is used for the production of forged rings for the internal elements of the VVER-1000 nuclear reactor. This steel is guaranteed to ensure the performance of this element and its structural integrity during the entire service life, but the new generation VVER has a larger damaging dose of neutrons falling on the material of the core baffle. Designed service life, in such conditions, is achievable to ensure by currently developed new austenitic steel with increased resistance to radiation swelling and embrittlement. An additional requirement for the material of the core baffle is a given grain size - not larger than G3 according to GOST 5639. Grinding the grain size in austenitic steel is possible only at the stage of hot plastic deformation of the workpiece (forging). The final technological operation, in which the formation of the structure and properties of the metal occurs, is heat treatment, in which the forged rings of the core baffle are heated to a high temperature, followed by cooling in water (hardening without polymorphic transformation). The temperature and duration of heating for quenching should ensure the production of homogeneous austenite in the absence of enlargement of the grain structure formed by forging. This article presents a comparative assessment of the effect of exposure temperature and duration on the complex of mechanical properties and the tendency to grain growth of new austenitic steel and used steel $08 \mathrm{H} 18 \mathrm{~N} 10 \mathrm{~T}$, as well as determining the optimal parameters of heating and holding for quenching of forged ring from new steel for the core baffle.
\end{abstract}

Keywords: core baffle, austenitic steel, heat treatment, grain size, mechanical properties.

УДК: 669-156.3

\section{Влияние параметров закалки на структуру и свойства радиационно-стойкой аустенитной стали для внутрикорпусной выгородки ВВЭР}

\author{
Теплухина И. В. ${ }^{1}$, Цветков А. С. ${ }^{\dagger, 1,2}$, Косульникова А. В. ${ }^{1}$ \\ ${ }^{1}$ НИЦ «Курчатовский институт» - ЦНИИ КМ «Прометей», ул. Шпалерная 49, С.-Петербург, 191015, Россия \\ ${ }^{2}$ Санкт-Петербургский политехнический университет Петра Великого, ул. Политехническая, 29, С.-Петербург, \\ 195251, Россия
}

Выгородка является одним из основных элементов внутрикорпусных устройств водо-водяного энергетического реактора и служит для защиты корпуса реактора от нейтронного облучения. Материал выгородки ВВЭР испытывает наибольшие радиационные нагрузки и имеет максимальную температуру вследствие $\gamma$-разогрева в результате облучения. Нейтронное облучение приводит к радиационному распуханию, снижению пластичности и трещиностойкости материала. Для изготовления колец внутрикорпусной выгородки используется сталь марки 08X18Н10Т. В ВВЭР-1000 эта сталь гарантированно обеспечивает работоспособность данного элемента и его конструктивную целостность в течение всего срока службы, однако ВВЭР нового поколения имеют бо́льшую повреждающую дозу нейтронов, приходящуюся на материал выгородки. Обеспечение работоспособности в таких 
условиях возможно только при использовании новой композиции аустенитной стали с повышенной стойкостью против радиационного распухания и охрупчивания. Дополнительным требованием к материалу выгородки является ограничение размера зерна - не крупнее G3 по ГОСТ 5639. Измельчение размера зерна для стали, имеющей аустенитную структуру, возможно только на этапе горячей пластической деформации заготовки (ковки). Завершающей технологической операцией, при которой происходит окончательное формирование структуры и свойств металла, является термическая обработка, в качестве которой для заготовок колец выгородки применяется нагрев до высокой температуры с последующим охлаждением в воде (закалка без полиморфного превращения). Температура и продолжительность нагрева под закалку должны обеспечивать получение однородного аустенита при отсутствии роста аустенитного зерна, сформированного ковкой. В данной статье представлена сравнительная оценка влияния температурно-временных параметров нагрева под закалку на комплекс механических свойств и склонность к росту зерна новой аустенитной стали и стали марки 08X18Н10Т. Определены оптимальные параметры нагрева под закалку (температура нагрева и время выдержки) заготовок выгородки из новой стали.

Ключевые слова: выгородка, аустенитная сталь, термическая обработка, размер зерна, механические свойства.

\section{1. Введение}

Выгородка является одним из основных элементов внутрикорпусных устройств (ВКУ) водо-водяного энергетического реактора (ВВЭР) и служит для защиты корпуса реактора от нейтронного облучения. Выгородка ВВЭР представляет собой цилиндрическую конструкцию с внешним диаметром около 3.5 м, состоящую из четырех колец, скрепленных между собой шпильками и зафиксированных друг относительно друга штифтами. Обеспечение конструктивной целостности ВКУ ВВЭР необходимо для безопасной эксплуатации АЭС во всех эксплуатационных и аварийных режимах. При обосновании срока службы ВВЭР выгородка ВКУ является критическим элементом с точки зрения определения срока эксплуатации, так как испытывает наибольшие радиационные нагрузки и имеет максимальную температуру вследствие $\gamma$-разогрева в результате облучения.

Для изготовления колец внутрикорпусной выгородки ВВЭР-1000 используется сталь марки 08Х18Н10Т. ВВЭР нового поколения имеют увеличенный ресурс и бо́льшую повреждающую дозу нейтронов, приходящуюся на материал выгородки. За 60 лет эксплуатации максимальная повреждающая доза нейтронов на материал выгородки ВКУ реакторов ВВЭР-1000 превышает 100 сна, а для реакторов ВВЭР-1200 и ВВЭР-ТОИ составляет более 150 сна $[1,2]$. Нейтронное облучение приводит к снижению пластичности и трещиностойкости материала $[3,4]$, а радиационное распухание значительно усиливает этот эффект $[5,6]$. При высоком уровне радиационного распухания (>10-15\%) происходит охрупчивание материала до пластичности, близкой к нулевой, а также резкое падение прочности и трещиностойкости [7].

Сочетание низких свойств материала и напряжений может привести к преждевременному разрушению выгородки и потере ее работоспособности. Таким образом, работоспособность внутрикорпусной выгородки реакторов новых проектов за пределами проектного срока службы не может быть гарантирована при консервативном прогнозе радиационного распухания в случае, если она будет изготовлена из использующейся в настоящее время стали марки 08X18Н10T [8].
Для обеспечения работоспособности выгородки для ее изготовления необходимо применить новую сталь, которая была бы более устойчива к воздействию эксплуатационных факторов.

В настоящее время специалистами НИЦ «Курчатовский институт» - ЦНИИ КМ «Прометей» проводятся работы по созданию новой радиационностойкой стали для выгородки - 10Х16Н25M2Т. По результатам облучения опытных образцов в ионном ускорителе до доз, превышающих 150 сна, новая сталь имеет высокое сопротивление радиационному распуханию и охрупчиванию по сравнению с применяемой сталью. Химический состав стали (после обеднения матрицы материала никелем в результате радиационного облучения) обеспечивает отсутствие протекания частичного фазового $\mathrm{Fe}_{\gamma}-\mathrm{Fe}_{\alpha}$ превращения, результатом которого является появление хрупковязкого перехода (не свойственного аустенитным материалам в исходном состоянии) и охрупчивание материала [8]. Одновременно проводятся работы по разработке промышленной технологии производства крупногабаритных заготовок для колец внутрикорпусной выгородки из новой стали $[9,10]$. Химический состав стали и технологии изготовления из нее заготовок должны обеспечивать получение требуемых механических и служебных свойств металла и регламентированный размер зерна (не крупнее G3 по ГОСТ 5639).

В качестве термической обработки заготовок колец выгородки из аустенитной стали применяется нагрев до высокой температуры с последующим охлаждением в воде (закалка без полиморфного превращения). Температура и продолжительность нагрева под закалку должны обеспечивать получение однородной структуры аустенита при отсутствии роста зерна. Неоднородность аустенита перед закалкой может повлечь за собой химическую неоднородность, что, в свою очередь, может стать причиной неоднородности исходных механических свойств и зеренной структуры. При эксплуатации под влиянием нейтронного облучения химическая неоднородность может привести к неоднородности распухания и появлению участков, в которых будет возможно протекание частичного фазового $\mathrm{Fe}_{\gamma}-\mathrm{Fe}_{\alpha}$ превращения [11,12]. Кроме того, крупный размер зерна 
в стали с аустенитной структурой оказывает влияние и на уровень механических характеристик [13].

Учитывая, что зерно в аустенитной стали невозможно измельчить термической обработкой из-за отсутствия в ней полиморфных превращений, высокотемпературный нагрев под закалку не должен приводить к росту зерна, сформированного в заготовке в процессе ее ковки. Получение же требуемого размера зерна необходимо обеспечить после всех стадий металлургического изготовления $[14,15]$ в частности после термической обработки, которая является завершающей технологической операцией, приводящей к окончательному формированию структуры и свойств. Соответственно параметры термической обработки должны обеспечивать получение однородного аустенита при отсутствии роста зерна в процессе высокотемпературной выдержки перед закалкой.

В данной статье представлены результаты сравнительной оценки влияния температуры и продолжительности нагрева под закалку на размер зерна и механические свойства новой аустенитной стали 10Х16Н25М2Т и используемой - 08X18Н10Т. Исследования проведены с целью научно-экспериментального обоснования основных технологических параметров термической обработки (температура нагрева и продолжительность выдержки) заготовки кольца из новой радиационно-стойкой аустенитной стали для внутрикорпусной выгородки ВВЭР.

\section{2. Материал для исследования и методика испытаний}

Настоящее исследование влияния параметров термической обработки на структуру и свойства сталей 08X18Н10Т и 10Х16Н25М2Т было проведено на металле опытно-модельных поковок. Выплавку стали проводили в вакуумно-индукционной электропечи. Металл был отлит в слитки массой 500 кг, из которых методом свободной ковки на молотах были откованы поковки размером $50 \times 300 \times 1000$ мм. Содержание основных легирующих элементов в исследованных плавках представлено в Табл. 1.
Для проведения исследований из поковок были вырезаны 20 темплетов размером $50 \times 60 \times 100$ мм, которые были термообработаны по режимам, представленным в Табл. 2. Термическая обработка темплетов проводилась в лабораторной камерной печи типа СНОЛ и заключалась в нагреве до заданной температуры, выдержке и последующем охлаждении в воде. При проведении термической обработки температура и продолжительность выдержки контролировалась по показаниям контрольной термопары, установленной в середине садки.

После термической обработки из каждого темплета были изготовлены образцы для определения механических свойств при растяжении при температурах 20 (по 2 образца тип III № 6 по ГОСТ 1497) и $350^{\circ} \mathrm{C}$ (по 2 образца тип III № 6 по ГОСТ 9651). Испытания на растяжение были проведены на испытательной машине Instron по ГОСТ 1497 и ГОСТ 9651 соответственно. Исследование микроструктуры проводилось с использованием оптического микроскопа Techno Meiji IM 7200 на микрошлифах после электролитического травления в $10 \%$ водном растворе щавелевой кислоты. Определение размера зерна проводилось в соответствии с ГОСТ 5639, а также с использованием программного обеспечения для анализа изображений Thixomet Pro.

\section{3. Результаты исследований и их обсуждение}

\section{1. Исследование механических свойств}

Как показали результаты испытаний на растяжение, требуемый уровень механических свойств при температурах испытания 20 и $350^{\circ} \mathrm{C}$ для обеих сталей был обеспечен после всех режимов термической обработки. Результаты механических испытаний при температуре $20^{\circ} \mathrm{C}$ представлены на Рис. 1 (для применяемой стали марки 08X18H10T) и на Рис. 2 (для новой стали марки 10Х16H25M2T).

Прочностные характеристики стали 08X18H10T при температуре испытания $20^{\circ} \mathrm{C}$ монотонно снижаются с увеличением температуры нагрева и времени выдержки. Наиболее сильно заметно снижение значений временного сопротивления разрыву при температурах

Табл. 1. Химический состав исследованного металла, мас.\%.

Table 1. Chemical composition of studied metal, wt.\%.

\begin{tabular}{|c|c|c|c|c|c|c|c|c|c|}
\hline $\begin{array}{c}\text { Studied metal } \\
\text { Исследованный металл }\end{array}$ & $\mathrm{C}$ & $\mathrm{Cr}$ & $\mathrm{Ni}$ & $\mathrm{Mo}$ & $\mathrm{Ti}$ & $\mathrm{Si}$ & $\mathrm{Mn}$ & $\mathrm{S}$ & $\mathrm{P}$ \\
\hline $\begin{array}{c}\text { Steel 10H16N25M2T } \\
\text { Сталь 10Х16Н25M2T }\end{array}$ & 0.081 & 15.47 & 24.33 & 2.49 & 0.70 & 0.51 & 1.66 & 0.003 & 0.032 \\
\hline $\begin{array}{c}\text { Steel 08H18N10T } \\
\text { Сталь 08Х18Н10T }\end{array}$ & 0.071 & 17.50 & 10.20 & 0.01 & 0.53 & 0.52 & 1.71 & 0.002 & 0.028 \\
\hline
\end{tabular}

табл. 2. Режимы термической обработки темплетов.

Table 2. Heat treatment modes of templates.

\begin{tabular}{|c|c|c|c|c|c|}
\hline $\begin{array}{c}\text { Temperature, }{ }^{\circ} \mathrm{C} \\
\text { Температура, }{ }^{\circ} \mathrm{C}\end{array}$ & 900 & 1000 & 1050 & 1100 & 1150 \\
\hline $\begin{array}{c}\text { Ехролure duration, } \mathrm{h} \\
\text { Продолжительность выдержки, ч }\end{array}$ & $1,2,4,8$ & $1,2,4,8$ & $1,2,4,8$ & $1,2,4,8$ & $1,2,4,8$ \\
\hline
\end{tabular}




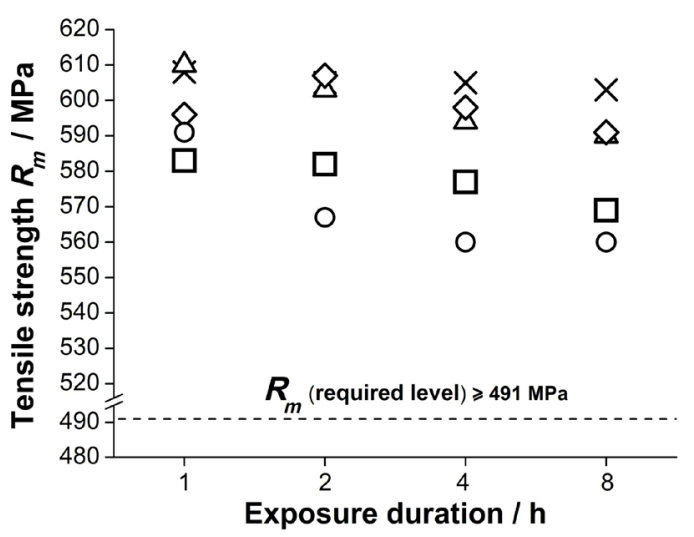

Exposure temperature: $X 900 \Delta 1000 \diamond 1050 \square 1100 \bigcirc 1150$

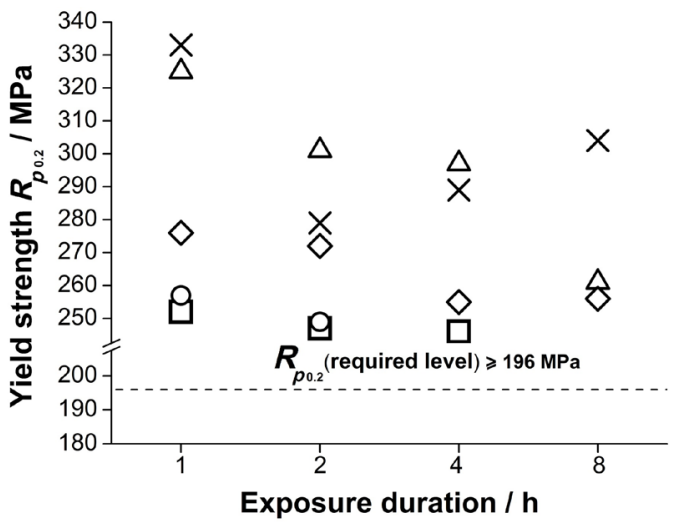

Exposure temperature: $X 900 \Delta 1000 \diamond 1050 \square 1100 \bigcirc 1150$

Рис. 1. Зависимость значений временного сопротивления разрыву $R_{m}$ (а) и условного предела текучести $R_{p 0.2}(\mathrm{~b})$ при $20^{\circ} \mathrm{C}$ для стали 08X18Н10Т от температуры и продолжительности выдержки.

Fig. 1. Dependence of tensile strength $R_{m}$ (a) and yield strength $R_{p 0.2}(\mathrm{~b})$ values at $20^{\circ} \mathrm{C}$ of steel $08 \mathrm{H} 18 \mathrm{~N} 10 \mathrm{~T}$ from exposure temperature and its duration.

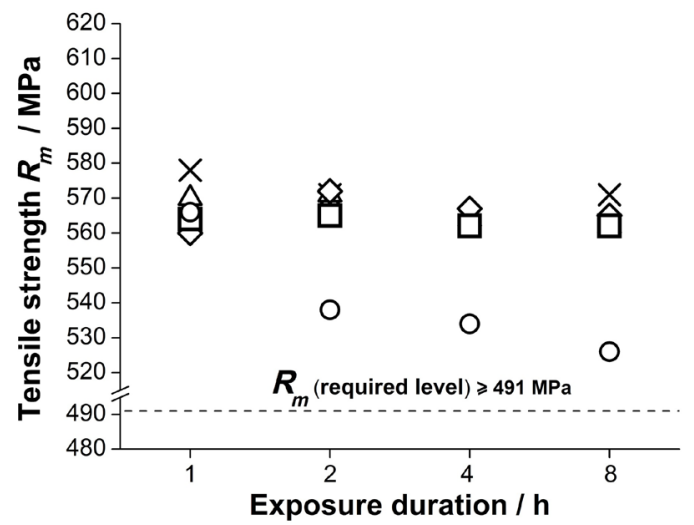

Exposure temperature: $\times 900 \Delta 1000 \diamond 1050 \square 1100 \bigcirc 1150$

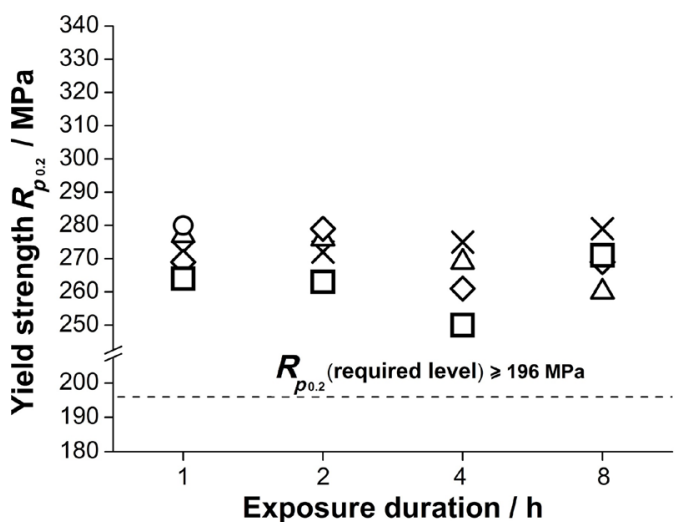

Exposure temperature: $X 900 \Delta 1000 \diamond 1050 \square 1100 \bigcirc 1150$

b

Рис. 2. Зависимость значений временного сопротивления разрыву $R_{m}$ (а) и условного предела текучести $R_{p 0.2}(\mathrm{~b})$ при $20^{\circ} \mathrm{C}$ для стали 10Х16Н25М2Т от температуры и продолжительности выдержки.

Fig. 2. Dependence of tensile strength $R_{m}$ (a) and yield strength $R_{p 0.2}$ (b) values at $20^{\circ} \mathrm{C}$ of steel $10 \mathrm{H} 16 \mathrm{~N} 25 \mathrm{M} 2 \mathrm{~T}$ from exposure temperature and its duration.

нагрева 1100 и $1150^{\circ} \mathrm{C}$ при выдержках свыше 2-х часов (Рис. 1a).

Уровень значений временного сопротивления разрыву и условного предела текучести в новой стали 10Х16Н25М2Т при температуре испытания $20^{\circ} \mathrm{C}$ отличается большей стабильностью (Рис. 2), чем в стали 08X18Н10Т. Существенное снижение временного сопротивления разрыву происходит только при температуре нагрева $1150^{\circ} \mathrm{C}$ при выдержках свыше 2-х часов. Как показали последующие металлографические исследования зеренной структуры, это связано с интенсивным ростом зерна при этих режимах термической обработки. При остальных исследованных режимах заметного снижения данных характеристик не наблюдается, что говорит о меньшей чувствительности новой стали к температуре нагрева по сравнению с применяемой сталью.

Следует отметить, что величина значений временного сопротивления разрыву при $350^{\circ} \mathrm{C}$ в новой стали $10 \mathrm{X} 16 \mathrm{H} 25 \mathrm{M} 2 \mathrm{~T}$ выше примерно на $10 \%$, чем в стали 08X18H10T, а прочностные характеристики при данной температуре испытания (также как и при температуре испытания $20^{\circ} \mathrm{C}$ ) характеризуются большей стабильностью. Кроме того, результаты испытаний показали, что для стали марки 08X18H10T нагрев до температур 1100 (продолжительностью 8 часов) и $1150^{\circ} \mathrm{C}$ (продолжительностью свыше 2-х часов) вызывает снижение предела текучести при температуре $350^{\circ} \mathrm{C}$ до предельно допустимых значений, незначительно превышающих требуемый уровень.

\section{2. Исследование микроструктурь и определение среднего размера зерна}

В состоянии без термической обработки исследуемый металл сталей 08X18Н10T и 10Х16Н25M2Т имел аустенитную структуру с размером зерна G7-G8 и G5-G6 соответственно. Зависимость изменения среднего размера зерна от температуры нагрева под закалку и продолжительности выдержки представлена на Рис. 3.

Как видно из полученных результатов, выдержки продолжительностью до 8-ми часов при температурах 
нагрева $900-1050^{\circ} \mathrm{C}$ практически не оказывают влияния на размер зерна стали 08X18Н10T (незначительный рост наблюдается только после выдержек свыше 4-x часов при температурах нагрева $1000-1050^{\circ} \mathrm{C}$ ). При температурах нагрева $1100-1150^{\circ} \mathrm{C}$ и выдержках свыше 2-х часов наблюдается значительный рост зерна (при температуре нагрева $1150^{\circ} \mathrm{C}$ и выдержке 2 ч - средний размер зерна соответствует G1-G2). Характерная микроструктура исследованного материала при $\times 100$ представлена на Рис. 4 .

В отличии от стали 08X18Н10T в стали марки 10Х16Н25М2Т изменения среднего размера зерна аустенита не обнаружено в температурном интервале нагрева $900-1100^{\circ} \mathrm{C}$ практически во всем исследованном диапазоне выдержек. Рост зерна отмечен только после выдержки 8 часов при температуре нагрева $1100^{\circ} \mathrm{C}$. При температуре нагрева $1150^{\circ} \mathrm{C}$ после выдержки продолжительностью более 2-х часов также, как и в стали 08X18Н10T, наблюдается существенный рост аустенитного зерна до G1-G2. Характерная микроструктура стали марки 10Х16Н25M2Т при ×100 представлена на Рис. 5.

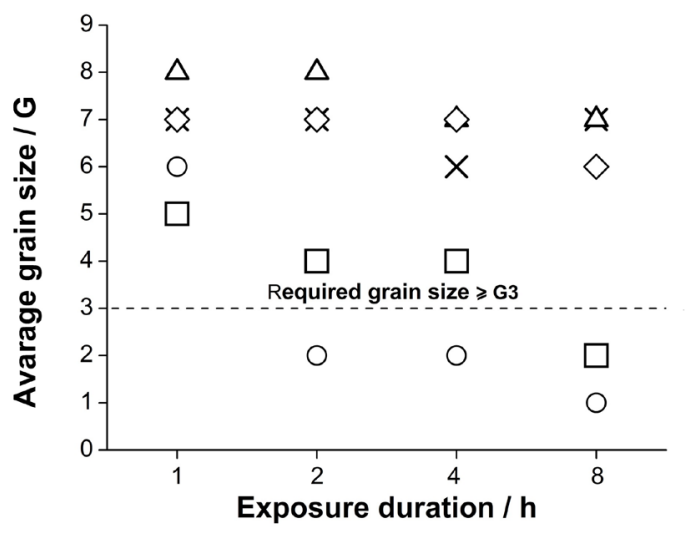

Exposure temperature: $X 900 \Delta 1000 \diamond 1050 \square 1100 \bigcirc 1150$
Увеличение среднего размера зерна в стали 08X18Н10Т уже при температурах нагрева $1000-1050^{\circ} \mathrm{C}$ после выдержек свыше 4-х часов и при $1100-1150^{\circ} \mathrm{C}$ после выдержек продолжительностью свыше 2-х часов представляется более значительными, нежели в стали марки 10Х16Н25М2Т обладающей меньшей склонностью к росту аустенитного зерна при высокотемпературных нагревах вплоть до $1100^{\circ} \mathrm{C}$ (выдержка 8 часов) и $1150^{\circ} \mathrm{C}$ (продолжительностью выдержки свыше 2-х часов).

\section{4. Заключение}

Исследование влияния температурно-временных параметров нагрева под закалку на структуру и свойства сталей для внутрикорпусной выгородки ВВЭР показало, что сталь марки 10Х16Н25М2Т обладает меньшей склонностью к росту зерна при нагреве. При высокотемпературной изотермической выдержке в температурном интервале $900-1100^{\circ} \mathrm{C}$ механические свойства и средний размер аустенитного зерна в новой стали практически не изменяются. Оптимальными параметрами нагрева под закалку заготовки из новой

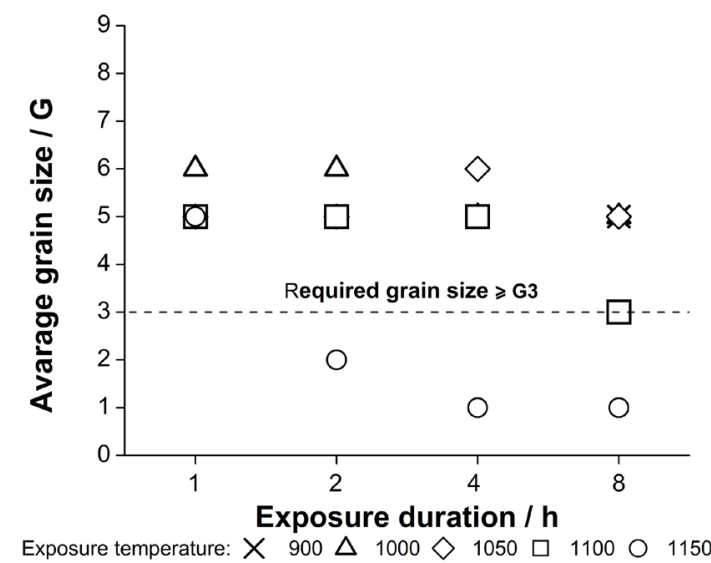

b

Рис. 3. Зависимость изменения среднего размера зерна сталей $08 \mathrm{X} 18 \mathrm{H} 10 \mathrm{~T}$ (а) и $10 \mathrm{X} 16 \mathrm{H} 25 \mathrm{M} 2 \mathrm{~T}$ (b) от температуры и продолжительности выдержки.

Fig. 3. Dependence of the change in the average grain size of steels $08 \mathrm{H} 18 \mathrm{~N} 10 \mathrm{~T}$ (a) and $10 \mathrm{H} 16 \mathrm{~N} 25 \mathrm{M} 2 \mathrm{~T}$ (b) from exposure temperature and its duration.

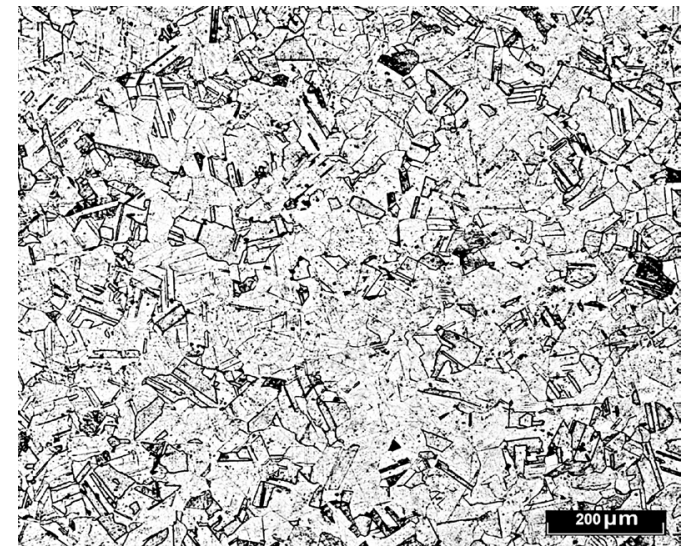

a

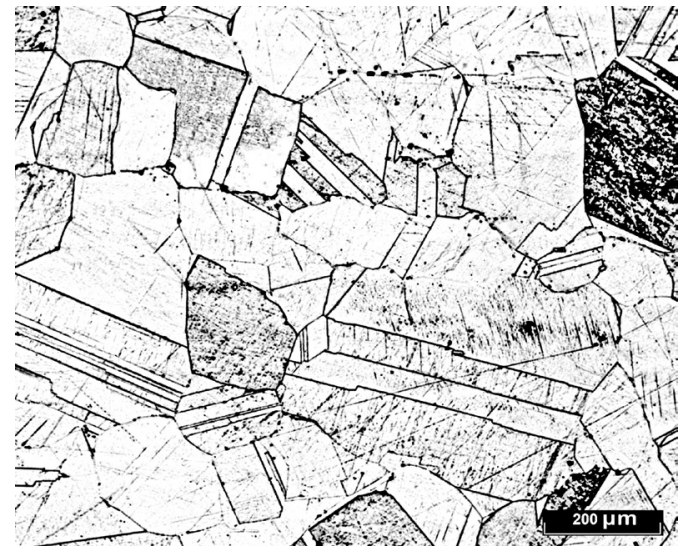

$\mathrm{b}$

Pис. 4. Микроструктура стали марки $08 \mathrm{X} 18 \mathrm{H} 10 \mathrm{~T}$ : температура $1050^{\circ} \mathrm{C}$, выдержка 4 ч - G7 (а), температура $1150^{\circ} \mathrm{C}$, выдержка 2 ч - G1-G2 (b).

Fig. 4. Microstructure of steel $08 \mathrm{H} 18 \mathrm{~N} 10 \mathrm{~T}$ : temperature $1050^{\circ} \mathrm{C}$, duration $4 \mathrm{~h}-\mathrm{G} 7$ (a), temperature $1150^{\circ} \mathrm{C}$, duration $2 \mathrm{~h}-\mathrm{G} 1-\mathrm{G} 2$ (b). 


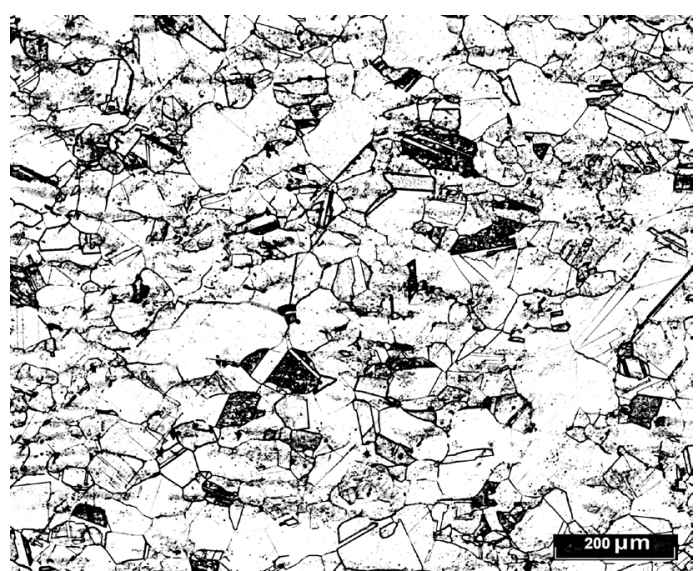

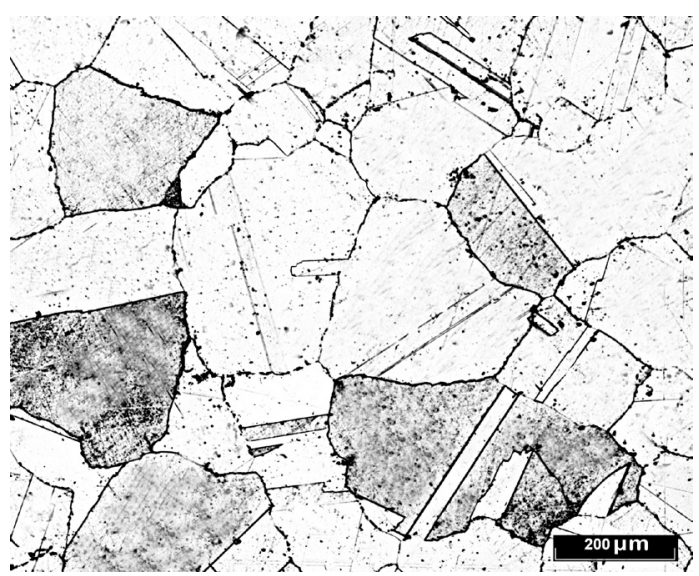

$\mathrm{b}$

Pис. 5. Микроструктура стали марки $10 \mathrm{X} 16 \mathrm{H} 25 \mathrm{M} 2 \mathrm{~T}$ : температура $1050^{\circ} \mathrm{C}$, выдержка 4 ч - G5-G6 (a), температура $1150^{\circ} \mathrm{C}$, выдержка 2 ч - G1-G2 (b).

Fig. 5. Microstructure of steel $10 \mathrm{H} 16 \mathrm{~N} 25 \mathrm{M} 2 \mathrm{~T}$ : temperature $1050^{\circ} \mathrm{C}$, duration $4 \mathrm{~h}-\mathrm{G} 5-\mathrm{G} 6$ (a), temperature $1150^{\circ} \mathrm{C}$, duration $2 \mathrm{~h}-\mathrm{G} 1-\mathrm{G} 2$ (b).

радиационно-стойкой аустенитной стали, обеспечивающими требуемый комплекс механических свойств и отсутствие склонности к росту зерна, являются: температура нагрева $1050-1100^{\circ} \mathrm{C}$ и выдержка $2-4$ ч.

В настоящее время полученные результаты используются для разработки промышленной технологии термической обработки заготовки кольца внутрикорпусной выгородки перспективного ВВЭР из новой стали.

\section{Литература/References}

1. G.P. Karzov, B.Z. Margolin. Rosenergoatom. 2, 8 (2015). (in Russian) [Г.П. Карзов, Б.3. Марголин. Росэнергоатом. 2, 8 (2015).]

2. V.A. Piminov, V.V. Evdokimenko. Rosenergoatom. 2, 16 (2015). (in Russian) [В. А. Пиминов, В.В.Евдокименко. Росэнергоатом. 2, 16 (2015).]

3. B.Z. Margolin, A. A. Sorokin. Strength of materials. 45, 125 (2013). Crossref

4. A. A. Sorokin, B. Z. Margolin, I. P. Kursevich, A. I. Minkin, V.S. Neustroev. Journal of Nuclear Materials. 444, 373 (2014). $\underline{\text { Crossref }}$

5. B. Z. Margolin, I. P. Kursevich, A. A. Sorokin, A. N. Lapin, V.I. Kohonov, V.S. Neustroev. Strength of materials. 6, 5 (2009). (in Russian) [Б.3. Марголин, И.П. Курсевич, А.А. Сорокин, А.Н. Лапин, В.И. Кохонов, В. С. Неустроев. Проблемы прочности. 6, 5 (2009).]

6. B.Z. Margolin, I.P. Kursevich, A.A. Sorokin, N. K. Vasina, V.S. Neustroev. Strength of materials. 2, 25 (2010). (in Russian) [Б.3. Марголин, И.П. Курсевич, А.А. Сорокин, Н.К. Васина, В.С. Неустроев. Проблемы прочности. 2, 25 (2010).]
7. V.S. Neustroev, F. A. Garner. Journal of nuclear materials. 386-388, 157 (2009). Crossref

8. I. P. Kursevich, G. P. Karzov, B. Z. Margolin, A. A. Sorokin, I. V. Teplukhina. Problems of material science. 3 (71), 146 (2012). (in Russian) [И.П. Курсевич, Г.П. Карзов, Б.3. Марголин, А.А. Сорокин, И.В. Теплухина. Вопросы материаловедения. 3 (71), 146 (2012).]

9. A. S. Tsvetkov, I. V. Teplukhina. Key engineering materials. 822, 53 (2019). Crossref

10. A.S. Tsvetkov, I. V. Teplukhina. Week of science SPbPU. Collection of the best reports. (2018) p. 94. (in Russian) [А. С. Цветков, И. В. Теплухина. Неделя науки СПбПУ. Лучшие доклады. (2018) с. 94.]

11. P.R. Okamoto, H. Wiedersich. Journal of nuclear materials. 53, 336 (1974). Crossref

12. D. L. Porter, E. L. Wood. Journal of nuclear materials. 83, 90 (1979). $\underline{\text { Crossref }}$

13. Yu. M. Lahtin. Metallovedenie i termicheskaja obrabotka metallov. Moscow, Metallurgiya (1983) 359 p. (in Russian) [Ю.М. Лахтин. Металловедение и термическая обработка металлов. Москва, Металлургия (1983) 359 с.]

14. V.I. Bogdanov, I.V. Teplukhina, A.S. Tsvetkov, T. I. Titova, N. A. Shul'gan, L. A. Milyakova. Letters on materials. 9 (3), 304 (2019). (in Russian) [В. И. Богданов, И.В. Теплухина, А.С. Цветков, Т.И. Титова, Н. А. Шульган, Л. А. Милякова. Письма о материалах. 9 (3), 304 (2019).] Crossref

15. I. V. Teplukhina, V.M. Golod, A.S. Tsvetkov. Week of science SPbPU. Collection of the best reports. (2016) p. 58. (in Russian) [И.В. Теплухина, В.М. Голод, А. С. Цветков. Неделя науки СПбПУ. Лучшие доклады. (2016) c. 58.] 